\title{
TRASTORNO DE ESPECTRO AUTISTA: DELIMITACIÓN LINGÜÍSTICA
}

\author{
JUAN CARLOS TORDERA YLLESCAS \\ Universidad Católica de Valencia. Grupo Val.Es.Co. \\ juan.tordera@uv.es
}

\begin{abstract}
Resumen
El propósito de este artículo es ofrecer una caracterización y sistematización del lenguaje de los pacientes con Trastorno de espectro autista (TEA) y la relación que existe entre los diferentes rasgos que los caracterizan. De manera especial, hemos distinguido entre los rasgos de los sujetos con TEA con déficit cognitivo y los rasgos lingüísticos de los sujetos que no tienen déficit cognitivo. Hemos distinguido, asimismo, las relaciones que tienen todas estas características lingüísticas con el componente pragmático del lenguaje. Esto es, queremos mostrar que muchas deficiencias de carácter fonético/fonológico o morfosintáctico están relacionadas con el componente pragmático. En nuestra opinión, el hecho de que el déficit pragmático tenga repercusiones en el fonético/fonológico y el morfosintáctico prueba que la pragmática está presente en el lenguaje como una totalidad y que, por consiguiente, la pragmática no debería ser concebida como un componente/módulo del lenguaje sino como una perspectiva (López GarcíaMolins, 1989 or Pons Bordería, 2005).
\end{abstract} TEA.

PALABRAS CLAVE: autismo, pragmática,

\section{Introducción teórica}

\subsection{Competencia lingüística y competencia comunicativa}

Antes de abordar el lenguaje de los pacientes con Trastorno de Espectro Autista $(\mathrm{TEA})^{1}$, creemos que es conveniente tratar, en primer lugar, una distinción lingüística que

\footnotetext{
${ }^{1}$ En Martos (1997: 25-27), se realiza una distinción nominal que, tal vez, merezca la pena introducir. En concreto, se hace una distinción entre Autismo típico o de Kanner, Trastorno Generalizado del Desarrollo (TGD) y Trastorno de Espectro Autista (TEA). Este tipo de trastornos mantienen entre sí una relación de inclusión. Todo Autismo típico es un TGD y un TEA y todo TGD es un TEA. Por ejemplo, el Síndrome de Rett es un TGD y, por tanto, un
} a linguistic point of view, a characterization and systematization of the language of patients with Autistic Spectrum Disorder, and the relations individuals with autistic spectrum with cognitive deficit and the linguistic features of individuals with autistic spectrum but without cognitive deficit. In addition to this, I will describe the relationship that pragmatic "component", that is, I want to show that many phonetic-phonological or morphosyntactical repercussions in phonetic-phonological or morphosyntactical aspects proves that Pragmatics are present in language as a whole and, therefore, perspective (López García-Molins, 1989 or Pons Bordería, 2005).

KEYWORDS: Autism, Pragmatics, Autistic
Spectrum
Disorder.. anong these characteristics. Specifically, I will 
puede revelarse clarificadora a la hora de entender dicho trastorno. La distinción a la que nos referimos es aquella que opondría los conceptos competencia lingüística y competencia comunicativa.

El término de competencia lingüística, introducido originariamente por Chomsky (1965 [1999]), se define como el conocimiento implícito que posee un hablante-oyente ideal sobre su propia lengua (Chomsky, 1965 [1999]: 7). Mediante esta competencia, un hablanteoyente ideal puede juzgar una cadena lingüística del tipo El niño golpeó la pelota como gramatical y otra cadena del tipo * La niño golpear pelota la como agramatical, como no gramatical. En cambio, la competencia comunicativa, término propuesto por Dell Hymes en 1966, se define como los conocimientos y las habilidades socioculturales que permiten a un hablante-oyente satisfacer sus intenciones discursivas (Castellà, 1992: 103-113).

Con el fin de esclarecer estos dos conceptos, se expondrá el siguiente ejemplo. Imaginemos una situación en la que tres sujetos quieren pedir a una camarera un zumo de naranja. El primero, que emitiría una frase como Señorita, ¿me puede poner un zumo de naranja?, sería competente lingüísticamente y comunicativamente, puesto que su oración es gramatical y su enunciado satisface su objetivo. El segundo sujeto, pongamos un extranjero que domina escasamente el idioma (o bien, un sujeto con afasia motora), solo logra enunciar beber naranja. Lingüísticamente, no sería un hablante competente, dado que su oración es agramatical, pero sí sería comunicativamente competente si la camarera, utilizando el contexto situacional, lograra saber a qué se refiere. Por último, el tercer sujeto, que también quiere beber un zumo de naranja, sí sabe decir Señorita, ¿me puede poner un zumo de naranja?, pero, pongamos que, por circunstancias personales adversas, no se muestra colaborativo, sino arisco y poco comunicativo. Este sujeto pronuncia una frase como Camarera, tráigame un puto zumo, y esta oración, aunque sea perfectamente gramatical, no se adecua a las circunstancias del enunciado. Por ello, puede ocurrir que un hablante sea competente lingüísticamente, pero no comunicativamente.

Esta distinción nos parece oportuna debido al hecho de que, como veremos más tarde, el déficit determinante de los sujetos del espectro autista posiblemente sea una alteración, no de la competencia lingüística (o gramatical), sino de la competencia comunicativa (o pragmática) $)^{2}$.

\footnotetext{
TEA. Sin embargo, el Autismo Atípico es un TEA y, no por ello, es un TGD. Por tanto, el término más general (incluyente) es el de TEA, que es el que, en el presente trabajo, utilizaremos.

${ }^{2}$ Quizá se podría pensar que el trastorno autista se puede explicar como un déficit en la actuación, término este también chomskiano, por la asociación “actuación>uso real>pragmática”. Sin embargo, esta idea no parece la correcta. La obra de Chomsky (1965 [1999]) está pensada en términos estrictamente sintácticos y no pragmáticos, y este término fue pensado exclusivamente para dar cuenta de las "erratas" sintácticas que cualquier hablanteoyente competente puede pronunciar (v.gr.: El chica- la chica es alta) o para dar cuenta de aquellas oraciones que nunca se dirían, pero que son gramaticales (v.gr.: El queso que el ratón al que el gato al que el perro mordió cazó comió era redondo). Y, lo que es más importante, Escandell Vidal (1996: 220-223) y el propio Chomsky, a quien la autora cita, no creen que se pueda equiparar la teoría de la pragmática con la teoría de la actuación, sino que el conocimiento pragmático mismo supone una competencia.
} 


\subsection{Teorías explicativas del autismo}

Entender cómo funciona la mente de un sujeto del espectro autista es una tarea harto compleja a la que los expertos han dedicado bastante atención. En las siguientes líneas, trataremos de resumir las dos aproximaciones más relevantes a esta cuestión, con el fin de comprender, en la medida de lo posible, la mente del autista.

Según se recoge en Belinchón, Igoa, y Rivière (1992: 744-745) y Tamarit Cuadrado (1990), dos son las teorías principales que han tratado de explicar el trastorno autista: (a) la Teoría de la mente, que incide especialmente en aspectos cognitivos, y (b) la Teoría afectiva, que incide en aspectos sociocognitivos.

La Teoría de la mente, defendida en 1985 por Baron-Cohen, Leslie y Frith, explica el autismo como una incapacidad para atribuir estados mentales a los otros, como por ejemplo la capacidad para inferir lo que otro $\mathrm{cree}^{3}$. A esta capacidad de reconocer lo que otros conocen, creen o piensan se la denomina capacidad metarrepresentacional. Según estos autores, los niños del espectro autista presentan un déficit cognitivo que mengua o restringe su capacidad metarrepresentacional. Desde un punto de vista lingüístico, este déficit es interesante, tal como se ejemplificará más abajo, puesto que la capacidad del hombre para transmitir información descansa en buena medida en la capacidad de inferirla y esta última habilidad está ligada al reconocimiento de las intenciones del emisor. Por tanto, si alguien no es capaz de tener en cuenta lo que el otro conoce, cree o sabe, la capacidad de inferencia se verá mermada y, por ende, la comunicación misma.

Por otro lado, la Teoría afectiva, defendida en 1983 por Hobson, parte del supuesto de que el trastorno autista tiene una causa emocional-afectiva. En concreto, esta teoría defiende que los niños del espectro autista no vienen preparados biológicamente para el contacto afectivo. La tesis de esta teoría se puede resumir en los siguientes cuatro puntos:

1) Los niños no saben interactuar adecuadamente, porque no comprenden el esquema “acción-reacción”, lo que, comunicativamente, implica el desconocimiento de las pautas de conducta de la conversación por las que, por ejemplo, una intervención iniciativa incita una intervención reactiva (Briz Gómez y Grupo Val.Es.Co., 2003: 17-19);

2) Al no interactuar con los demás, no pueden crear un mundo propio y común. Su conocimiento se construye a partir de sus experiencias directas, pero nunca a partir de las experiencias ajenas;

3) La carencia de participación en la experiencia intersubjetiva conllevará una alteración en el reconocimiento de los sentimientos, pensamientos, deseos, etc., de los otros así como en la capacidad de abstracción y simbolización;

\footnotetext{
${ }^{3}$ Esta hipótesis se ha visto corroborada empíricamente. Mediante dos muñecas, Sally y Anne, se representa cómo Sally coloca dentro de su cesta una canica y sale fuera de escena. Entonces, Anne aprovecha este momento para colocar dentro de su caja una canica. Si se le preguntara al niño con autismo dónde buscará Sally su canica al entrar, este no tiene en cuenta lo que sabe Sally sino lo que él mismo sabe (porque lo ha visto). El niño con autismo responde que Sally buscará su canica en la caja.
} 
4) Los posibles déficits cognitivos y lingüísticos serán consecuencia del particular desarrollo socioafectivo así como de la capacidad de simbolizar, la cual se adquiere socialmente.

La Teoría de la mente y la Teoría afectiva plantean dos hipótesis razonables que la práctica clínica no ha podido falsear, por lo que, en principio, ambas teorías son igualmente válidas y, por ello, merecen tenerse en cuenta en la investigación de sujetos con trastornos del espectro autista.

\section{Caracterización lingüística}

Una vez definido el trastorno en términos lingüísticos (i.e., como una alteración de la competencia comunicativa) y una vez ofrecidas las teorías etiológicas del Trastorno de Espectro Autista (i.e., Teoría de la mente y Teoría afectiva), el objetivo de las siguientes líneas es ofrecer una breve descripción de aquellos rasgos lingüísticos más significativos que caracterizan a los niños de espectro autista, aunque, como señalan Belinchón, Igoa, y Rivière (1992: 736), no todos estas anomalías o desviaciones lingüísticas son exclusivas o específicas de este trastorno.

En primer lugar, cabe señalar que no todos los sujetos de espectro autista muestran una conducta lingüística homogénea. Grosso modo, se podrían distinguir dos grupos: (1) niños autistas que no adquieren el lenguaje y (2) niños autistas que adquieren los aspectos formales del lenguaje (es decir: los aspectos fonológicos y sintácticos), pero no así el funcional (el componente pragmático) (Belinchón, Igoa, y Rivière, 1992: 735-746, Martos, 2001: §4 y 6; y Martos y Ayuda, 2002: 59-60).

Una de las posibles variables que se han de tener en cuenta en el estudio de estas posibilidades es el de su desarrollo cognitivo (Martos, 2001: §6; y Martos y Ayuda, 2002: 60). Por un lado, cabría distinguir aquellos niños de espectro autista a cuyo trastorno cabría sumar el retraso mental (y que suponen tres cuartas partes de la población autista), frente a aquellos cuyo trastorno no está asociado con ningún déficit cognitivo adicional. Normalmente, los primeros son los que tendrán mayores dificultades en adquirir el lenguaje natural (si es que lo adquieren), mientras que los niños autistas de alto funcionamiento y los niños con Síndrome de Asperger ${ }^{4}$ representan aquellos quienes presentan problemas funcionales de la comunicación pero no formales.

Así pues, atendiendo a esta distinción, se elaborará un doble descripción del lenguaje autista. En primer lugar, se describirá el lenguaje de aquellos niños que no han conseguido adquirir el lenguaje, o lo han hecho de forma muy restringida; y, posteriormente, se describirá el lenguaje de aquellos niños que sí lo han adquirido pero de una forma deficitaria en el componente funcional.

\footnotetext{
${ }^{4}$ Un subtipo del anterior.
} 


\subsection{Niños que no han desarrollado un lenguaje formal ni funcional}

En las siguientes líneas, se van a describir las primeras etapas de desarrollo del lenguaje del niño de espectro autista. Asimismo, cabe tener en cuenta que, dado que muchos niños no llegan a desarrollar un verdadero lenguaje, estos se estancan en esta etapa (Martos y Ayuda, 2002: 58).

El niño con Trastorno de Espectro Autista (normalmente, abreviado como TEA), desde sus primeros meses de vida, muestra dificultades para simbolizar (Monsalve, 2001: §1), es decir, es incapaz de representar una realidad conocida mediante otra. Así, por ejemplo, el juguete de un coche representa (simboliza) un coche auténtico. El niño de espectro autista, por el contrario, es incapaz de realizar esta representación. Por ello, este niño no cogerá el coche ni lo conducirá como si se tratara de un coche auténtico, sino que, a lo sumo, se quedará admirado por una característica o una parte de este (por ejemplo, la rueda del coche). La dificultad de simbolizar tiene importantes consecuencias para el desarrollo lingüístico, dado que el lenguaje, obviamente, implica simbolizar: las palabras representan los objetos que designan, aunque no son los objetos mismos.

Los niños de espectro autista presentan igualmente problemas en las funciones de la comunicación. Es decir, tienen problemas en regular el comportamiento de los demás, en establecer relaciones y en fijar la atención conjunta. Todos estos problemas pueden resumirse de la siguiente forma ${ }^{5}$ :

1) Respecto a la regulación de la conducta del otro, el niño de espectro autista no muestra interés por compartir los estados emocionales (intersubjetividad primaria) y tampoco por cambiar los estados mentales de los demás (intersubjetividad secundaria) (Belinchón, Igoa, y Rivière, 1992: 744; y Monsalve, 2001: §2). Es decir, tal como proponía la Teoría afectiva, no se detecta un deseo de intercambio de experiencias. Por ello, no es de extrañar que las conductas protoimperativas, que tratan de lograr cambios en su contexto, presenten anomalías y que las conductas protodeclarativas, que tratan de influir en los estados mentales de los otros, no aparezcan (Belinchón, Igoa, y Rivière, 1992: 743-744; y Monsalve, 2001: §2).

2) En referencia al establecimiento de las relaciones sociales y de la atención conjunta, cuyo objetivo común es el de cambiar el estado mental de los otros (Monsalve, 2001:2). En el primer caso, el niño no muestra ningún interés por interactuar con el otro, lo que se pone de manifiesto desde muy pronto por el hecho de que no se muestra sensible a las expresiones faciales, ni a los timbres de voz ni entonaciones de los demás (Monsalve, 2001: §2). Como no se desarrollan estos esquemas interactivos, se producen graves deficiencias en el lenguaje, dado que el "lenguaje no es más que la evolución de todos los esquemas interactivos anteriores (Monsalve, 2001: §2)”. Es decir, si el niño de espectro autista no tiene interés por comunicarse y el lenguaje es un instrumento de comunicación ¿para qué va a realizar el niño el esfuerzo de aprender a hablar?

\footnotetext{
${ }^{5}$ Véase Monsalve (2001: 1 y 2)
} 
3) Con respecto al problema de la atención conjunta, cabe señalar que, al no tener en cuenta el estado mental del otro, el niño de espectro autista no sabe que puede cambiarlo con el propósito de que el otro fije su atención en lo que a él le interesa. Por consiguiente, no aparecerá la mirada conjunta, es decir, el niño no mostrará interés en que el adulto se fije en lo que él está mirando (Monsalve, 2001: §2).

Otro aspecto importante que cabe tener en cuenta con respecto a los niños de espectro autista es el de la prosodia. Los niños de espectro autista "presentan anomalías en los contornos prosódicos prelingüísticos característicos de los niños normales (Belinchón, Igoa, y Rivière, 1992: 740)”. Por tanto, la disprosodia, o alteración prosódica, es un fenómeno que se puede registrar muy tempranamente. Como se verá en el siguiente punto, creemos que este rasgo es relacionado lingüística y neurolingüísticamente con la alteración pragmática.

El último fenómeno lingüístico que caracteriza las primeras etapas evolutivas, y que explica, posiblemente, el estancamiento lingüístico de muchos niños de espectro autista es el lenguaje ecolálico (Martos y Ayuda, 2002: 59 y Belinchón, Igoa, y Rivière, 1992: 742). Según Martos y Ayuda (2002: 59), los niños de espectro autista “acceden a éste [el lenguaje oral] mediante la ecolalia (inmediata o diferida), con escasez de lenguaje creativo". De acuerdo con Martos y Ayuda (2002: 59) y Belinchón, Igoa, y Rivière (1992: 742), este fenómeno se explicaría por el hecho de que los niños de espectro autista analizan el lenguaje de forma holística, es decir, lo perciben como un todo sin descomponer las distintas partes del enunciado y sin entender el sentido global. Por ello, sus emisiones lingüísticas se limitan a emisiones repetitivas, es decir, emisiones no creativas que pudieran implicar una descomposición o un análisis del lenguaje.

\subsection{Niños con lenguaje formal pero no funcional}

Atendiendo a los distintos componentes lingüísticos, el lenguaje adquirido formalmente de un niño con autismo se caracteriza por los siguientes rasgos.

\subsubsection{Plano fonético-fonológico}

En primer lugar, cabe señalar que, en el plano segmental, los niños autistas no presentan diferencias notorias en el desarrollo de su componente fonológico (Belinchón, Igoa, y Rivière, 1992: 739; y Monsalve, 2001: §3.1.). La discriminación fonológica así como su posterior adquisición no presentan ningún tipo de particularidad evolutiva reseñable.

En el plano suprasegmental o prosódico, por el contrario, sí existen, como ya adelantamos, diferencias notables (Tamarit Cuadrado, 1990, Belinchón, Igoa, y Rivière, 1992: 740-741, y Monsalve, 2001: §3.1.). Según se recoge en Belinchón, Igoa, y Rivière (1992: 740), se produce un déficit tanto en la percepción como en la producción. Perceptivamente, los niños con autismo no tienen en cuenta las claves prosódicas, por lo 
que no consiguen interpretar adecuadamente el cambio en el tono, la intensidad, etc. Productivamente, los niños con autismo presentan alteraciones prosódicas en el volumen, ritmo, entonación y tono del habla. Es más, producen "una impresión característica de monotonía, arritmicidad, descontrol o inadecuación del volumen de voz y falta de relación entre entonación y sentido que se ha reflejado en muchas descripciones clínicas (Belinchón, Igoa, y Rivière, 1992: 740)”. Por esta alteración prosódica, los niños de espectro autista no acentúan correctamente las palabras de contenido, (nombres, verbos o adjetivos), que son tónicas o las palabras funcionales (preposiciones o conjunciones), que son átonas (Tamarit Cuadrado, 1990 y Belinchón, Igoa, y Rivière, 1992: 740)

Las alteraciones prosódicas suponen un fenómeno lingüístico que ha de ser tenido en consideración, puesto que pueden estar ligadas a las alteraciones pragmáticas que trataremos posteriormente. Con el componente prosódico, por ejemplo, el hablante expresa diferentes significados e intenciones. Por ejemplo, con un enunciado declarativo el hablante quiere trasmitir un tipo de información al receptor; con un enunciado interrogativo, por el contrario, el hablante quiere conocer información de su receptor:

(1) Ha venido la mujer del jefe a la fiesta vs. ¿Ha venido la mujer del jefe a la fiesta?

El componente prosódico sirven igualmente para delimitar y señalar las funciones informativas ${ }^{6}$ o tema-rema ${ }^{7}$ :

(2) - ¿DÓNDE ha ido Juan? - A LA FIESTA ha ido

Pues bien, según Belinchón, Igoa, y Rivière (1992: 746), estos niños no pueden emplear "el acento de contraste en las palabras que conllevan información nueva”. No logran reconocer qué es nuevo y qué es viejo.

Por último, también existen datos neurolingüísticos que deben ser tenidos en consideración, y que son especialmente importantes, como veremos más tarde, en el plano pragmático. Según se recoge en Kaplan (1992: 422-423), los sujetos que sufren una lesión en el hemisferio derecho muestran síntomas de disprosodia. Y este síntoma conlleva también problemas para interpretar el lenguaje no literal, como es el caso de los chistes o el establecimiento de inferencias para entender el sentido de una narración.

\subsubsection{Plano morfosintáctico}

En general, el componente morfosintáctico no se ve severamente afectado por el autismo. De hecho, parecen emplear las reglas morfosintácticas correctamente. Por tanto, su competencia gramatical se adecua al grado de desarrollo cognitivo alcanzado (Belinchón, Igoa, y Rivière, 1992: 738-739; y Monsalve, 2001).

\footnotetext{
${ }^{6}$ Véase Gutiérrez Ordóñez (1997: 27 y 36); e Hidalgo y Quilis (2004: 262-263).

${ }^{7}$ Como se tratará en el punto 2.2.2, también presentan problemas con otros elementos morfosintácticos, como es el caso del artículo que juega un papel informativo en la organización tema-rema
} 
Entre los escasos déficits reseñables, cabe citar los problemas que los niños de espectro autista presentan con algunos morfemas como los morfemas temporales y personales del verbo (Belinchón, Igoa, y Rivière, 1992: 736 y 738-739 y Monsalve, 2001). Por ejemplo, los fenómenos de regularización son más frecuentes en niños de espectro autista que con niños no autistas (v.gr.: "andé” frente a "anduve”).

Estos niños suelen tener igualmente problemas con el artículo como elemento que cumple la función informativa de identificar partes ya conocidas en el discurso (v.gr.: Esta mañana ha venido una mujer (rema). La mujer (tema) ha preguntado por ti).

Otro fenómeno muy característico de los niños de espectro autista es lo que los expertos en la materia denominan como inversión pronominal (Belinchón, Igoa, y Rivière, 1992: 736). El niño presenta dificultades en la utilización de los pronombres y los morfemas personales. En lugar de enunciar una oración como Yo tengo hambre, un niño del espectro autista emitiría una oración pragmáticamente marcada como lo sería El niño tiene hambre o Juan tiene hambre en las que el niño y Juan harían referencia al propio sujeto.

Como se recoge en Martos y Ayuda (2002: 59) y Belinchón, Igoa, y Rivière (1992: 741), también presentan problemas en el uso de los elementos deícticos (este, ese, aquel, aquí, ahí, allî), es decir, en elementos cuyo significado viene delimitado por el contexto. Teniendo en cuenta que el contexto es una realidad interiorizada, es decir, que forma parte de los conocimientos que posee el hablante, se puede relacionar esta carencia con los presupuestos de la Teoría de la mente. Para que un sujeto de espectro autista pudiese enunciar una oración como Coge aquel libro y no Coge ese libro habría de tener en cuenta que el objeto deseado es un objeto visualmente accesible para su receptor y que, por tanto, formará parte de su contexto (cognitivo). Es decir, el uso de los deícticos exige una capacidad metarrepresentacional de la que carecen los sujetos de espectro autista.

Por último, cabe señalar que el lenguaje del niño con espectro autista no suele ser complejo, sino que más bien tiende a ser sencillo incluso lacónico (Tamarit Cuadrado: 1990, Monsalve, 2001: §3.1.). Por ello, su discurso también se caracteriza por la parquedad en el uso de conjunciones y conectores pragmáticos.

\subsubsection{Plano léxico-semántico}

En primer lugar, los niños de espectro autista presentan dificultades con las palabras a cuyo significante no le corresponde un único significado, como las palabras polisémicas y homonímicas (Tamarit Cuadrado: 1990; y Monsalve, 2001: §3.1.). Así por ejemplo, ante una oración como Tu padre está en el banco, el niño autista no encontraría ambigüedades (banco =entidad financiera; banco = lugar público para tomar asiento), sino que solo tendría en cuenta el significado más prototípico (banco = lugar público para tomar asiento)”.

Nuevamente, cabe relacionar este hecho con el déficit pragmático. Un sujeto no autista tiende a solucionar las ambigüedades contextualmente en busca de un significado coherente o, como dirían Sperber y Wilson (1986 [1994]:169-179), la relevancia determinaría el contexto adecuado para el significado de las palabras. El receptor ha de tener en cuenta las creencias, supuestos e intenciones de su emisor y poner en funcionamiento su capacidad metarrepresentacional. Sin embargo, tal como defiende la Teoría de la mente, los sujetos de 
espectro autista presentan una disfuncionalidad de dicha capacidad y, por tanto, no pueden interpretar correctamente las ambigüedades léxicas.

Los niños de espectro autista presentan, asimismo, problemas con el empleo de vocabulario abstracto (Martos y Ayuda, 2002: 59; y Belinchón, Igoa, y Rivière, 1992: 736) como son magnitud, laxitud, hipótesis, etc., y no suelen utilizar en su discurso verba cognoscendi como pensar, creer, considerar, etc. (Martos y Ayuda, 2002: 59).

En Belinchón, Igoa, y Rivière (1992: 741) y Monsalve (2001: §3.1.), se recoge también el hecho de que los niños de espectro autista no poseen ningún trastorno en la organización semántica, sino más bien en la utilización de su conocimiento semántico. Esto quiere decir que si un sujeto no autista adscribe los elementos manzana, pera y limón a la categoría fruta, el sujeto de espectro autista organizará semánticamente de igual modo las unidades. Sin embargo, no obtiene ninguna ventaja cognitiva a la hora de procesar la información. Por lo tanto, un niño de espectro autista adscribirá conceptos como los de médico, enfermera, paciente al mismo campo semántico que un niño "normal”, aunque no obtendría ningún efecto de facilitación en la comprensión del fragmento El médico pidió que le extrajeran sangre al paciente y la enfermera así lo hizo.

Para llevar a cabo la interpretación correcta, se habría de producir lo que, en psicolingüística, se conoce como priming semántico, es decir, el procesamiento de una palabra (palabra priming o activadora) acelera la comprensión de otra palabra (palabra target u objetivo) del mismo campo semántico. En el ejemplo propuesto, el procesamiento de la palabra médico debería acelerar el procesamiento de las palabras paciente o enfermera. Sin embargo, un sujeto de espectro autista no obtendría estos efectos facilitadores de procesamiento. Por tanto, podríamos concluir que ni el contexto extralingüístico ni el contexto lingüístico tiene efectos facilitadores del procesamiento de la información.

\subsubsection{Plano pragmático}

Como se recoge en Belinchón, Igoa, y Rivière (1992: 745), tanto los defensores de la Teoría de la Mente como los defensores de la Teoría afectiva parecen estar de acuerdo con que los niños de espectro autistas sufren "limitaciones y anomalías que afectarán muy esencialmente al componente pragmático del lenguaje, en tanto que éste depende decisivamente de contextos mentales, de inferencias mentalistas derivadas de la estrategia intencional [...] y, en definitiva, de las posibilidades de acceso al mundo interno de los que se comunican con el lenguaje”.

Como se ha señalado anteriormente, uno de los rasgos que más y mejor caracterizan el lenguaje de los niños con autismo es el de su falta de intencionalidad: ni parecen mostrar intención comunicativa ni reconocen la intención informativa del interlocutor (Martos: 2001: §6; y Monsalve, 2001: §3). No tienen interés en comunicarse ni en entender a los demás. El niño de espectro autista, por ejemplo, no tiene interés en compartir ni sus experiencias ni creencias (Monsalve, 2001: §3.1.) y tampoco parece que tenga en cuenta los estados mentales de su interlocutor (Tamarit Cuadrado, 1990 y Belinchón, Igoa, y Rivière, 1992: 744-745). Es decir, el niño con espectro autista vive en su mundo interior, y no 
necesita compartirlo ni que otros se lo cambien. Por ello, no es de extrañar la ausencia de los verba cognoscendi en estos niños (Yo creo que..., Juan cree que.., etc.), ya que no necesita compartir sus experiencias personales ni tener información acerca de las que tienen los demás.

Otro rasgo pragmático que caracterizan el lenguaje autista es la comprensión literal del mensaje, hecho que obviamente está ligado con el fenómeno de la intencionalidad (Martos, 2001: §6; y Monsalve, 2001: §3.1.). En casos como estos, el niño autista es incapaz de entender qué ha querido decir el emisor deteniéndose exclusivamente en qué ha dicho. Utilizando otras palabras, comprende la fuerza locutiva de un enunciado, pero no su fuerza ilocutiva. Esto explica que los niños autistas sean incapaces de entender los actos indirectos, las metáforas, las bromas, las ironías, etc. (Martos y Ayuda, 2002: 59).

En el caso concreto de los actos indirectos, el niño entiende el significado de una oración solo a partir de la suma de las partes que la componen, y, por tanto, es incapaz de captar su significado global. Por ejemplo, ante un enunciado como ¿Me puedes pasar la sal?, el niño entiende una pregunta y no una petición. Ante este enunciado reaccionará con una respuesta afirmativa o negativa, pero no realizará ninguna acción. Es decir, contrario a la situación pragmática normal, el niño entiende que su interlocutor le ha preguntado si tiene la capacidad (poder) de acercarle al interlocutor (pasarle) la sustancia blanca que condimenta la comida (la sal), pero no entiende la fuerza ilocutiva del enunciado.

En el caso de las metáforas, nuevamente, el niño concibe el lenguaje de forma literal. No comprende que a una palabra se le pueda adjudicar significados “desviados”. Así por ejemplo, en los enunciados del tipo Juan es un lince o Marta es una ballena el niño autista puede entender que Juan es un félido parecido a un gato o que María es un mamífero que vive en el medio acuático, pero no que Juan es astuto o que María es una mujer algo rellenita.

Obviamente los niños autistas tampoco comprenden las bromas y las ironías ${ }^{8}$, pues para interpretar el sentido cómico es necesario realizar un esfuerzo inferencial que va más allá del significado de las partes que componen el mensaje. Es lo que necesitamos para entender un chiste como:

(3) - ¿Cómo se dice eyaculación precoz en japonés? -Ya'stá (deformación de ya está)

El chiste juega con el hecho de que la expresión española ya'stá, además de significar que algo ha concluido de forma rápida, tiene un supuesto parecido fonético con el japonés ${ }^{9}$; y que, por lo tanto, se puede relacionar jocosamente esta expresión con la sensación de insatisfacción que la eyaculación precoz deja en uno de los amantes.

\footnotetext{
${ }^{8}$ Véase Ruiz y Padilla (2008).

${ }^{9}$ Evidentemente, lo de menos es que esto sea así.
} 
Dicha información no está explícita en el chiste, sino que el interlocutor ha de inferirla $^{10}$. Es decir, es necesario ir más allá de lo literal para extraer el sentido cómico de los chistes. El niño autista carece de esta capacidad; la interpretación sería, por tanto, literal.

Un tercer fenómeno pragmático con en el que estos niños tienen problemas es con la distinción informativa entre lo temático y remático. Según Monsalve (2001: §3.1.), el niño de espectro autista presentaría problemas en esta distinción, porque el hecho de dominarla supone distinguir lo que es conocido para el interlocutor de lo que no lo es, y, como se ha descrito anteriormente, el niño de espectro autista no tiene en cuenta el estado mental de su interlocutor.

Los sujetos de espectro autista se caracterizan también por disponer de una tipología de actos de habla muy restringida ${ }^{11}$ y por no respetar las máximas conversacionales de Grice (Belinchón, Igoa, y Rivière, 1992: 744-745). Dado que, según la Teoría afectiva, la necesidad interactiva de estos sujetos se ve reducida a la mínima expresión, puede interpretarse esta mengua de actos de habla como un ajuste pragmático a las necesidades comunicativas de estos sujetos. Respecto a las máximas de Grice, por un lado, cabe señalar que su no deseo de comunicarse hace comprensible su no aceptación (o su desconocimiento) del principio de cooperación. Por otro lado, todo ello se complica significativamente si tenemos en cuenta que, en no pocas ocasiones, las máximas se violan, por lo que se han de inferir implicaturas y significados contextuales muy específicos.

Otro fenómeno en el que el niño de espectro autista presenta algunas dificultades es en el dominio de las reglas pragmáticas que dominan la construcción de cualquier conversación (Tamarit Cuadrado, 1990 y Monsalve, 2001: 3.1.). Así por ejemplo, el niño presenta problemas en tomar el turno conversacional y mantenerlo ${ }^{12}$, y sus intervenciones se reducen, a veces, al par adyacente "pregunta-respuesta”. Esto no es de extrañar, si se tiene en cuenta que la Teoría afectiva postulaba que los sujetos de espectro autista no sienten la necesidad de relacionarse y, por ende, de comunicarse. Por tanto, sus interacciones, en el caso de que se dieran, se han de reducir a interacciones mínimas.

Dadas las características propias de estos sujetos, no es de extrañar que presenten alteraciones en las narraciones (Belinchón, Igoa, y Rivière, 1992: 744-745). Su falta de deseo comunicativo conlleva expresiones lacónicas y breves. Ello implica también no compartir lo que le ha podido ocurrir, es decir, sus experiencias personales pasadas. Como se ha indicado, desde la Teoría de la mente se propone que la incapacidad metarrepresentacional mengua la capacidad inferencial, lo cual es una condición necesaria para narrar.

Una narración pone en evidencia que el significado textual no es composicional sino supracomposicional, es decir, que el significado global es más que la suma de las partes. Así

\footnotetext{
${ }^{10}$ De hecho, el efecto cómico recae, sobre todo, en la capacidad inferencial del interlocutor, como lo demuestra el hecho de que un chiste que es explicado (o explicitado) ya no nos resulta tan gracioso.

11 Prácticamente se reduce a actos directivos y, parcialmente, a actos representativos -pero no para referir experiencias pasadas o creencias- en detrimento de los expresivos, comisivos y declarativos.

${ }^{12}$ Según Tamarit Cuadrado (1990), los problemas en la toma y mantenimiento de turno se podrían explicar por el hecho de que «la conversación es un flujo constante de información modulada por el conocimiento que tenemos de la otra persona; en este sentido, cada conversación es un ejercicio permanente de atribuciones mentales». A esto, cabría añadir que, para iniciar un turno, un prerrequisito sería la existencia de intencionalidad.
} 
se evidencia en ejemplos clásicos como María se ha casado y se ha quedado embarazada y María se ha quedado embarazada y se ha casado. El orden de los enunciados conlleva distintas inferencias que son difíciles de captar para el sujeto de espectro autista.

También cabe señalar que toda narración se articula y cohesiona mediante conectores y que estos elementos también pueden activar distintas inferencias. Por ejemplo, en un enunciado como Juan es pobre pero honrado se activa la inferencia: 'la honradez y la pobreza no suelen ser cualidades compartidas'. El sujeto de espectro autista, tal como se indicó anteriormente, tiene problemas con los conectores y, posiblemente, dicho problema se explique por su incapacidad para inferir información no explícita, información necesaria para la correcta interpretación de los conectores.

En las narraciones, por otra parte, se producen fenómenos de concordancia temporal o consecutio témporum (por ejemplo: Juan dice que vendrá frente a Juan dijo que vendría), y la dificultad de los niños autistas con los morfemas verbales acrecienta los problemas de tanto de comprensión como de vertebración de los contenidos.

Otro hecho que es interesante tener en consideración es el de la supuesta localización neurológica del componente pragmático. Según Escandell Vidal (1996: 219), el componente pragmático parece ubicarse en el hemisferio derecho. De acuerdo con esta autora, esto explicaría que existan hablantes con componentes formales (fonología y sintaxis), conservados, ubicados en el hemisferio izquierdo, y con componentes funcionales alterados, ubicados en el hemisferio derecho. Algunos sujetos de espectro autista podrían presentar alteraciones en el hemisferio derecho pero no en el izquierdo, por lo que se podría explicar por qué adquieren el lenguaje formal pero no saben cómo usarlo ${ }^{13}$. A lo que se añade que el componente prosódico se ubica también en el hemisferio derecho, por lo que no parecería descabellado relacionar la disprosodia con la alteración pragmática.

Otros autores no compartirían completamente la afirmación de que el déficit autista se explique por una alteración en el hemisferio derecho que afecte al componente pragmático y al prosódico simultáneamente. En opinión de Kaplan (1992: 422-423), los sujetos con una lesión en el hemisferio derecho que manifestan disprosodia no presentan problemas en "comprender el papel que el acento oracional desempeña en el establecimiento de la información conocida y desconocida o en la determinación de lo que se conoce como fuerza ilocutiva de una expresión”. De estas palabras, se desprende que el componente pragmático y el prosódico sí parecerían estar disociados.

A pesar de la objeción de Kaplan, podemos pensar, sin embargo, que dada la relación estrecha entre lo prosódico y lo pragmático, y la interrelación que existe entre la disprosodia y la conducta comunicativa en el espectro autista, la ubicación neurológica de estos dos componentes, etc., no parece muy descabellado afirmar que, de algún modo, lo prosódico y lo pragmático guardan una relación muy estrecha.

\footnotetext{
${ }^{13}$ Dicha hipótesis se ve corroborada por el estudio de Artigas (1999: 121). En este trabajo, se afirma que, en 1996, un grupo de investigadores, J. Shields, R. Varley, P. Broks y A. Simpson, demostraron que los niños con trastornos pragmáticos y sociales (en concreto, niños con Trastorno Específico del Lenguaje del componente semántico/pragmático y niños autistas de alto funcionamiento) mostraban una disfunción en el hemisferio derecho.
} 


\subsubsection{Otros aspectos de la comunicación}

Desde el punto de vista paralingüístico y kinésico, la comunicación autista se caracteriza por alteraciones en el empleo de los gestos comunicativos, de la mirada, de la entonación, de la acentuación, etc., con el fin de acompañar, enriquecer o reformular el lenguaje oral (Monsalve, 2001: §3.1.) o con el fin de tomar y mantener el turno comunicativo (Belinchón, Igoa, y Rivière, 1992: 746). Estos niños muestran más dificultades con los gestos expresivos que con los instrumentales, es decir, les cuesta más entender los gestos con los que su receptor expresa su estado de ánimo que los gestos que utiliza su receptor para señalar, por ejemplo, un objeto.

\section{Conclusiones}

En el presente trabajo, se ha tratado de establecer unas líneas descriptivas del Trastorno de Espectro Autista y, en tanto que lingüistas, nuestra atención ha recaído precisamente en una caracterización de los fenómenos que afectan al lenguaje.

Como es conocido por los expertos, el sujeto que padece Trastorno de Espectro Autista presenta un déficit característico en el componente funcional del lenguaje, por lo que el presente trabajo ha prestado un especial interés por el componente pragmático. Pero también se ha intentado establecer conexiones entre el componente funcional del lenguaje y el resto de componentes del lenguaje. Creemos que, partiendo de un criterio estrictamente lingüístico, es fácil explicar el resto de alteraciones del lenguaje a partir de la deficiencia pragmática. De este modo, se ha tratado de relacionar la pragmática con las alteraciones en el uso del artículo, de los deícticos, de los pronombres personales, de los conectores y de los morfemas temporales así como la disprosodia, la dificultad de resolución de ambigüedades léxicas, la ausencia de facilitación de procesamiento por el priming semántico, o la brevedad de las oraciones. Siendo esto así, podríamos concluir que la pragmática es un “componente” cuya alteración lingüística puede afectar a otros componentes como el gramatical o el prosódico. Así pues, podemos decir que la pragmática debe impregnar todo el análisis del lenguaje autista.

Este trabajo intenta, asimismo, abrir nuevas hipótesis de investigación. Lo llamativo de los sujetos con Trastorno de Espectro Autista no es que el componente funcional y el componente formal de su lenguaje puedan verse alterados, sino que existan sujetos que presenten una alteración funcional sin que se dé una alteración formal. Esto nos plantea la pregunta de cómo es posible que un sujeto desarrolle formalmente un auténtico lenguaje sin que a este sujeto le suponga ninguna utilidad esta adquisición. Es decir, cabría formularse la cuestión de si el instinto del lenguaje es tal que se ha de cumplir sin que, por ello, existan ventajas adaptativas. Siendo esto así, sería necesario cuestionar entonces si el instinto del lenguaje solo afecta al componente formal del lenguaje.

Para responder a ello tendríamos que relacionar esta pregunta con las últimas investigaciones sociobiológicas. Desde la sociobiología, se ha defendido que lo innato del hombre es su tendencia a relacionarse. Tezanos Tortajada (2006: 34-71) afirma que, en el proceso de hominización, el hombre perdió fortaleza física, su dentadura y mandíbula se 
hicieron menos aptas para el ataque y para las comidas duras, la piel se hizo más fina y perdió más pelo, sus garras perdieron capacidad de ataque o de agarre, etc. En pocas palabras, la evolución nos hizo menos adecuados para el medio natural, pero la paradoja es que, a pesar de nuestras deficiencias físicas, la realidad nos muestra que seguimos estando bastante bien adaptados a dicho medio. Según los sociobiólogos, esta adaptación solo es explicable por la tendencia del hombre a relacionarse, por su tendencia natural a transmitir información, por su tendencia a compartir una cultura. Por lo tanto, más que hablar de un instinto del lenguaje, deberíamos hablar quizás de un instinto a la sociabilidad en el que el lenguaje humano es un instrumento importante, pero no el único. A nuestro juicio, es este instinto social del que carecen los niños de espectro autista. La mayoría de los niños de espectro autista no desarrollan un lenguaje, porque para ellos es un instrumento inútil.

Nos gustaría hacer hincapié, por último, en el problema de la lateralización del “componente" funcional en el hemisferio derecho y su relación con el componente prosódico. Siendo esto así, y partiendo de que la comunicación es el fin último del lenguaje, cabría desechar la idea de preeminencia o superioridad del hemisferio izquierdo en el lenguaje. Sin negar la importancia de dicho hemisferio para el desarrollo del lenguaje, también sería interesante disponer de estudios evolutivos que pudieran ratificar la importancia del hemisferio derecho en el desarrollo del lenguaje (si es que lo hubo). Desde un punto teórico, podríamos justificar que "el mono solo con una gramática” no hubiera sido capaz de desarrollar un auténtico lenguaje.

\section{Referencias bibliográficas}

Artigas, Josep (1999): “El lenguaje en los trastornos autistas”, publicado en la Revista de Neurología, número 28 (2), pàgs. 118-123.

Belinchón, Mercedes, Igoa, José Manuel y Rivière, Angel (1992): "Las alteraciones del lenguaje desde la perspectiva psicolingüística”, capítulo 15 de Psicología del lenguaje. Valladolid. Ed. Trotta.

Briz Gómez, Emilio Antonio y Grupo Val.Es.Co. (2003): "Un sistema de unidades para el estudio del lenguaje coloquial", Revista Oralia, vol. 6, 7-61 17-19. Arco-Libros. Madrid.

Castellà, Josep M. (1992): De la frase al text. Barcelona. Empúries.

Chomsky, Noam (1965 [1999]): Aspectos de la teoría de la sintaxis. Barcelona. Gedisa.

Escandell Vidal, Mª . Victoria (1996): Introducción a la pragmática. Barcelona. Ed. Ariel.

Gutiérrez Ordóñez, Salvador (1997): Temas, remas, focos, tópicos y comentarios. Madrid. Ed. ArcoLibros.

Hidalgo Navarro, Antonio y Quilis Merín, Mercedes (2004): Fonética y fonologías españolas. Valencia. Ed. Tirant lo Blanch.

Kaplan, David (1992): Introducción a la neurolingüística y al estudio de los trastornos del lenguaje. Madrid. Ed. Visor.

López García-Molins, Ángel (1989): Fundamentos de lingüística perceptiva.

Martos, J. (2001): “Autismo: un trastorno penetrante del Desarrollo” en Martos, J. y Pérez, J. (comp) Autismo. Un enfoque orientado a la formación en logopedia. Ed. NAU Llibres.

Martos, J. (1997): “Espectro autista: Una reflexión desde la práctica clínica” en El tratamiento del autismo. Nuevas Perspectivas, de À. Rivière, J. Martos (comp), MTAASS. APNA. Madrid. 
Martos, J. y Ayuda, R. (2002): “Comunicación y lenguaje en el espectro autista: el autismo y la disfasia” en Revista de Neurología, n 32 , Supl. 1.

Monsalve, C. (2001): "Comunicación y lenguaje en autismo: claves para el buen trabajo de un logopeda” en Martos, J. y Pérez, J. (comp) Autismo. Un enfoque orientado a la formación en logopedia. Ed. NAU Llibres.

Pons Bordería, Salvador (2005): La enseñanza de la pragmática en la clase de ELE. Madrid. ArcoLibros.

Ruiz Gurillo, Leonor y Xose A. Padilla García (eds.) (2008): Dime cómo ironizas y te diré quien eres: una aproximación pragmática a la ironía, Peter Lang, Frankfurt.

Sperber, Dan y Deirdre Wilson (1986 [1994]): La relevancia. Madrid. Visor.

Tamarit Cuadrado, Javier (1990): "Comunicación y autismo: Claves para un logopeda aventurero" ponencia de las Jornadas de Renovación Lopédica "Ciudad de Plasencia" disponible en www.asociacionalanda.org/pdf/articulos/autismo_logopeda.pdf.

Tezanos Tortajada, José Félix (2006): La explicación sociológica: una introducción a la Sociología. Madrid. Editorial UNED. 